ORIGINAL PAPER

\title{
Dipeptidyl peptidase IV in two human glioma cell lines
}

\author{
A. Šedo ${ }^{1,2}$, R. Malík ${ }^{1}$, K. Drbal', V. Lisá1, K. Vlašicová ${ }^{1}$, V. Mareš ${ }^{1}$
}

'Joint Laboratory of Cancer Cell Biology, 1st Institute of Medical Chemistry and Biochemistry of the 1st Faculty of Medicine, Charles University and Institute of Physiology, Academy of Sciences of the Czech Republic, Czech Republic and ${ }^{2}$ Laboratory of Cell Pathology, Institute of Experimental Medicine, Academy of Sciences of the Czech Republic, Czech Republic.

Accepted: 28/09/00

Key words: dipeptidyl peptidase IV, glioma cell lines, cell proliferation and differentiation

\section{SUMMARY}

There is growing evidence that dipeptidyl peptidase IV [DPP-IV, EC 3.4.14.5] takes part in the metabolism of biologically active peptides participating in the regulation of growth and transformation of glial cells. However, the knowledge on the DPP-IV expression in human glial and glioma cells is still very limited. In this study, using histochemical and biochemical techniques, the DPP-IV activity was demonstrated in two commercially available human glioma cell lines of different transformation degree, as represented by U373 astrocytoma (Grade III) and U87 glioblastoma multiforme (Grade IV) lines. Higher total activity of the enzyme, as well as its preferential localisation in the plasma membrane, was observed in U87 cells. Compared to U373 population, U87 cells were morphologically more pleiomorphic, they were cycling at lower rate and expressing less Glial Fibrillary Acidic Protein. The data revealed positive correlation between the degree of transformation of cells and activity of DPP-IV. Great difference in expression of this enzyme, together with the phenotypic differences of cells, makes these lines a suitable standard model for further studies of function of this enzyme in human glioma cells.

\section{INTRODUCTION}

Dipeptidyl peptidase IV (DPP-IV, EC 3.4.14.5), a member of the family of cell membrane proteases (Yaron and Naider, 1993) is identical to the T-cell activation antigen CD26 (Hegen et al., 1990) and to the adenosine deaminase binding protein (Kameoka et al., 1993). Due to both hydrolytic and nonhydrolytic mechanisms, DPP-IV is involved in a number of cell functions, such as cell to cell communication, cell activation, proliferation, adhesion, metastasising etc. (Bauvois et al., 1993; Johnson et al., 1993; _edo et al., 1996; Iwata and Morimoto, 1999). As reviewed previously, DPP-IV up-regulation is associated with cell differentiation in various cells and tissues (_edo and Kraml, 1994).

Although the enzyme was found in a variety of cells in various mammalian species, the data on its expression in nervous system cells are very rare. So far, only very low levels of the enzymatic activity, immunoreactivity and mRNA expression of DPPIV were found in rat glial cells (Hartel et al., 1988; 
Hildebrandt et al., 1991; Mentlein et al., 1990). On the other hand, significant levels of DPP-IV activity were demonstrated in rat C6 glioma cells ( $\breve{S e d o}$ and Revoltella, 1994). Our previous study provided evidence that DPP-IV activity upregulation, its subcellular redistribution and the change of pI-pattern are associated with differentiation of these cells (Šedo et al., 1998). There is growing evidence that the DPP-IV activity is of significance to the metabolism of biologically active peptides participating in the regulation of glial cell growth and transformation (Hoffmann et al., 1993; Mentlein et al., 1993). Therefore, it seems that the enzyme expression is regulated and switched on during some physiological and/or pathological processes in the nervous system. Data on the enzyme expression in human normal glial cells are not available. Up to now, DPP-IV activity was described only in a commercially not available clone (D-384) of human astrocytoma cell line G-CCM (Medeiros et al., 1991).

The aim of this study was to find an available human glioma cell model suitable for studies of DPP-IV role in transformation and growth related processes. Thus, we have examined the activity, intrapopulation and subcellular distribution of DPPIV in U373 and U87 glioma cell lines (ATCC, Rockwille, USA), which differ in the degree of malignity and the growth rate of the tumours formed after their transplantation to nude mice.

\section{MATERIALS AND METHODS}

\section{Chemicals}

The fluorogenic and histochemic substrates 7-(glycyl-L-prolylamido)-4-methylcoumarin (GP-NHMec) and 7-(glycyl-L-prolylamido)-4-methoxy- $\beta$-naphthylamide (GP-MNA) were from Bachem, Bubendorf, Switzerland. RNAase A, Nonidet 40, 7-amino4-methylcoumarin $\left(\mathrm{NH}_{2} \mathrm{Mec}\right), \mathrm{Zwittergent}^{3-12}\left(\mathrm{ZW}^{3-12}\right)$, Extravidin-Peroxidase, Bisbensimide H33258, foetal calf serum (FCS), salmon sperm DNA and trypsin/EDTA solution were from Sigma-Aldrich Prague, Czech Republic. Dulbecco's modified Eagle's medium (DMEM) was from Sevapharma, Prague, Czech Republic. Bovine and serum albumin fraction V (BSA) was from Serva, Heidelberg, Germany. Other common chemicals used were of the highest available purity and were obtained from various commercial sources.

\section{Cell cultures}

The human astrocytoma U373 and human glioblastoma multiforme U87 cell lines were obtained from ATCC, Rockwille, MD, USA. The cells were seeded at $1.2-1.3 \cdot 10^{4}$ cells $/ \mathrm{cm}^{2}$ in 10 $\mathrm{cm}$ diameter plastic Petri dishes (Nunc, Roskilde, Denmark). They were cultured at $37^{\circ} \mathrm{C}$ in DMEM supplemented with $10 \%$ FCS under a humidified (>90\%) atmosphere of $5 \% \mathrm{CO}_{2} / 95 \%$ air for $7-14$ days to reach confluence of about $75 \%$. The medium was exchanged every 5 days. The cell viability evaluated by trypan blue exclusion was always greater than $90 \%$. The cell morphology was examined on an inverted microscope (Nikon TMS, Tokyo, Japan).

For biochemical experiments, the cells were washed tree times with phosphate buffered saline (PBS; $137 \mathrm{mM} \mathrm{NaCl}, 2.68 \mathrm{mM} \mathrm{KCl}, 4 \mathrm{mM}$ $\mathrm{Na}_{2} \mathrm{HPO}_{4}, 1.76 \mathrm{mM} \mathrm{KH} \mathrm{PO}_{4}, \mathrm{pH}$ 7.4) and then removed from Petri dishes by scraping with a rubber policeman into PBS. Cells were counted by Coulter Counter Z2 (Krefeld, Germany) and cell suspensions were adjusted with PBS to about $10^{7}$ cells $/ \mathrm{ml}$. Cell suspension aliquots were solubilized by addition of $25 \mathrm{mM}$ Zwittergent ${ }^{3-12}\left(\mathrm{ZW}^{3-12}\right)$ for measurement of the total cellular enzyme activity.

\section{Cell growth curves}

The cells were seeded at density $3 \cdot 10^{3}$ (U87) or $3 \cdot 10^{4}$ (U373) cells/well in 96 well plate (Nunc, Roskilde, Denmark). Starting from day 3 after the plating, the cells were harvested in one-day interval by $0.2 \%$ trypsin $/ 0.02 \%$ EDTA solution in PBS. The number of cells was determined by Coulter Counter. Each point of the growth curve is a mean \pm SD from two independent experiments measured in triplicate.

\section{DNA Flow-cytometry}

The cells in the exponential phase of growth were detached by $0.2 \%$ trypsin/0.02\% EDTA solution in PBS and suspensions were fixed and stored in 70\% cold ethanol. For DNA staining, aliquots (about $10^{6}$ cells $/ \mathrm{ml}$ ) were transferred in PBS and incubated in a mixture of propidium iodide $(50 \mu \mathrm{g} / \mathrm{ml})$, RNAase $\mathrm{A}$ and $0.1 \%$ Nonidet 40 in PBS. The samples were measured by FACSort flow cytometer (Becton Dickinson, Mountain View CA, USA) and the data evaluated by WinMDI 2.8 software. 
Glial Fibrillary Acidic Protein (GFAP) Immunocytochemistry

GFAP was detected with monoclonal anti-GFAP GF-01 (Exbio, Prague, Czech Republic) antibody (1:25) and goat anti-mouse IgG FITC conjugate (Fab specific, 1:200) or biotin conjugated goat anti-mouse IgG (Fab specific, 1:300) followed by Extravidin-Peroxidase (1:100) and a conventional diaminobenzidine reaction enhanced by nickel chloride. All antibodies except for the anti-GFAP ones were from Sigma, St. Louis, USA. The cells were examined by transmission light- or epi-fluorescence microscope (Axioplan, Opton).

\section{Enzyme Histochemistry}

The cells grown on glass cover slips or on strips cut off the bottoms of culture Petri dishes were fixed in cold $\left(4^{\circ} \mathrm{C}\right)$ of acetone and chloroform (1:1) for 2 min and then incubated in GP-MNA and Fast Blue B (pH 7.4) over night at $4^{\circ} \mathrm{C}$. Subsequently, the specimens were washed in $4 \%$ paraformaldehyde over night at $4{ }^{\circ} \mathrm{C}$ followed by a water bath and mounting in Apathy syrup (Lojda, 1981). Matched slides, incubated without DPP-IV substrate, were used as controls of the staining specificity.

\section{Enzyme Biochemistry}

The DPP-IV activity was measured at $37^{\circ} \mathrm{C}$ with GP-NHMec at a final concentration of $200 \mu \mathrm{M}$ in PBS using continuous rate assays as described before (Šedo et al., 1989). The reaction was started by adding $50 \mu \mathrm{l}$ of enzyme sample into $1.95 \mathrm{ml}$ of pre-warmed substrate solution. The $\mathrm{NH}_{2} \mathrm{Mec}$ release from the substrate was monitored on a fluorimeter (Perkin-Elmer LS 50B) at excitation and emission wavelengths of $380 \mathrm{~nm}$ and $460 \mathrm{~nm}$, respectively. The assays were standardised with $\mathrm{NH}_{2} \mathrm{Mec}$ in the assay buffer. Enzyme activity was expressed as nkat/mg of total cellular protein or as

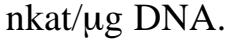

\section{Protein and DNA Estimation}

Total protein concentration in cell sample aliquots was determined according to Markwell et al. (1981) with BSA as a standard. DNA concentration was measured with bisbenzimide H33258 according to Brunk et al. (1979) with DNA from salmon sperm as an internal standard.

\section{RESULTS}

Morphology, proliferation and GFAP expression The U373 glioma population consisted of slim bipolar cells with relatively scanty cytoplasm and long processes. The population was relatively homogeneous and often orderly arranged along the longitudinal axes of cells. The U87 cells were morphologically less uniform, more plasmatic and often multipolar. Except some cells, the cell processes were shorter and wider. The cells grew often in small islands interconnected by bundles of longitudinally arranged cells. Population cell density in age-matched cultures were lower in U87 than in U373 cells. Small round particles were often found stuck to the more densely populated islands of U87 cells.

As revealed by cell growth curves (Fig. 1), the proliferation of U373 astrocytoma was faster than in U87 glioblastoma cell line under the same culture conditions. The doubling times in the exponential phase of growth were $31.5 \mathrm{~h}$ and $56.3 \mathrm{~h}$ for U373 and U87 cells, respectively. Similar growth difference was indicated by the number of S-phase cells as determined by flow cytometry $(20.7 \%$ in U373 vs. $7.8 \%$ in U87; Fig. 2). The majority of U373 cells were intensively stained for GFAP i.e. expressing astrocyte specific intermediate filaments. Staining of U87 cells was less intense and many of them were unstained (Fig. 3C,D).

\section{Enzyme Histochemistry}

As shown in Fig. 3A, DPP-IV activity was present only at the threshold levels in the majority of U373 cells. In a small part of the population, the DPP-IV activity was, however, quite intense and present both in the cell body cytoplasm and in the bipolar processes. DPP-IV positive cells occurred either solitarily or in small groups of approximately 2 to 6 cells. On the contrary, in U87 glioma line, DPP-IV positively stained cells were frequent. Fifty percent of the cells exhibited moderate and 20\% even a strong staining (Fig. 3B). The DPP-IV positive cells appeared either solitary or formed bands containing both moderately and densely stained cells. Smaller part of the population was unstained or contained only threshold levels of the DPP-IV reaction product. 


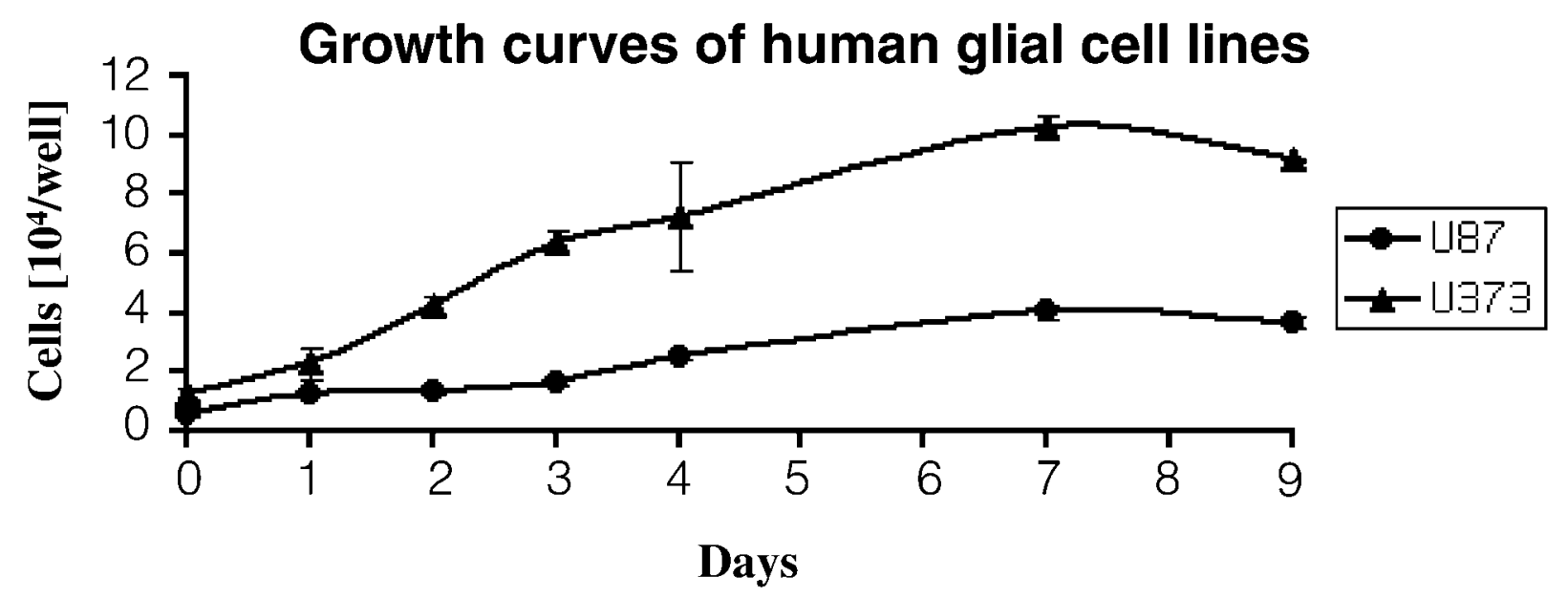

Fig. 1 - Growth curves of U373 and U87 glioma cells in culture.

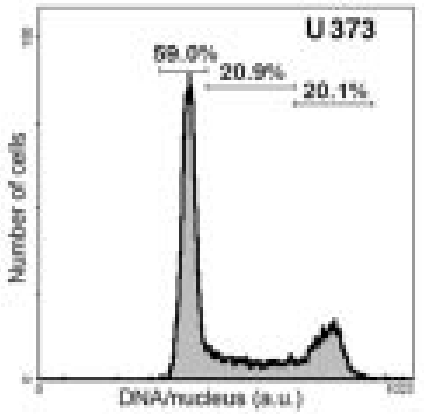

DPP-IV Biochemistry

The total cellular DPP-IV activity expressed per DNA was significantly higher in U87 than in U373 cells. When expressed per cellular protein, no significant difference was observed (Tab. 1). This can be explained by different protein concentration in both cell lines; the latter amounted to $0.017 \pm 0.009$ $\mathrm{mg} / \mu \mathrm{g}$ DNA and $0.030 \pm 0.004 \mathrm{mg} / \mu \mathrm{g}$ DNA in U373 and U87 cells, respectively.

The cell surface associated DPP-IV activity was significantly higher in U87 than in U373 cells. In contrast to U373 cells, the majority of DPP-IV activity in U87 population was localised in the plasma membrane.
Fig. 2 - DNA content distribution in U373 and U87 glioma cells in the exponential phase of growth.

\section{DISCUSSION}

The present study revealed activity of DPP-IV in U373 astrocytoma as well as in U87 glioblastoma multiforme cell lines by both histochemical and biochemical approach. Histochemically, great intrapopulation differences were observed in both cell lines. The higher activity in some cells of the population could reflect their clonal or cell-to-cell contact specifities. The actual impact of such factors on DPP-IV activity however remains to be examined. The incidence of DPP-IV positive cells revealed in both cell lines histochemically corresponds to the activity of this enzyme assayed biochemically, namely when expressed per DNA. The higher activity of DPP-IV in U87 cells corre-

Fig. 3 - Histochemistry of DPP-IV in U373 (A) and U87 (B) glioma cells using GP-MNA as a substrate. GFAP immunocytochemical staining of U373 (C) and U87 (D) cells. Axiophot, Zeiss, Nomarski phase contrast, magnification 400x. 
Imp. Sedo 11-02-2002 16:33 Pagina 61 
Table I

Dipeptidyl peptidase IV (DPP-IV) activity and distribution in human glioma cell lines

\begin{tabular}{llcc}
\hline & & U373 & U87 \\
\cline { 3 - 3 } DPP-IV Activity & & Cell line \\
\hline Cell surface-associated & nkat/mg protein & $12.77 \pm 5.12$ & $30.06 \pm 5.07$ \\
& nkat/ug DNA & $0.18 \pm 0.05$ & $0.95 \pm 0.28$ \\
Total cellular & nkat/mg protein & $40.65 \pm 8.06$ & $45.06 \pm 9.84$ \\
& nkat/ug DNA & $0.59 \pm 0.11$ & $1.35 \pm 0.29$ \\
\hline
\end{tabular}

Data are means \pm SD from at least 3 independent experiments in duplicates.

lates with lower proliferation rate, higher pleomorphy of cells, lower expression of marker of the degree of astrocyte differentiation GFAP as well as with higher malignity of tumours formed by transplantation of these cells to nude mice (glioblastoma IV and astrocytoma III for U87 and U373 cells, respectively). With respect to the supposed role of DPP-IV in cell adhesion it is worth mentioning that our preliminary results suggest that U87 cells are more prone to the trypsin-mediated detachment from the plastic dishes growth support (data not shown).

Interestingly, a higher DPP-IV activity was observed in some transformed cells, compared to their non-malignant counterparts. Up-regulation of this enzyme was described for instance in some haematological malignancies, thyroid carcinomas, basal cell carcinoma, breast carcinomas etc. (Iwata and Morimoto, 1999). The data on activity of this enzyme in normal human glial cells are, unfortunately, not available.

DPP-IV is also assumed to participate in the regulation of neuropeptide signaling (Mentlein et al. 1993) and in the proteolytic processing of some cytokines (Hoffmann et al. 1993), important in the pathogenesis of various diseases of nervous system including tumours (Meir, 1995). The molecular mechanism of substance P (SP) mediated signaling of proliferation in glial cells, together with one of SP receptor up-regulation $\left(\mathrm{NK}_{1}\right)$ in human malignant gliomas were recently described (Palma et al., 1999). It is noteworthy that signaling activity of SP is regulated by DPP-IV mediated limited proteolysis. The actual function of DPP-IV in glial/glioma cells of different phenotype awaits, however, further studies.

\section{ACKNOWLEDGEMENTS}

This work was supported by the Grant Agency of Charles University No. 58/1999/C and $1^{\text {st }}$ Medical Faculty of Charles University Research Project No. 206019-2 - "Oncology". Technical assistence of Mrs Ivana Zajanová and linguistic editing by Mrs Vesna Tot are greatly appreciated.

\section{REFERENCES}

Bauvois B., and Laouar A.: Distinct cellular functions mediated by haemopoietic cell-surface proteases. Adv. Neuroimmunol. 3, 171-181, 1993.

Brunk C.F., Jones K.C., and James T.W.: Assay for nanogram quantities of DNA in cellular homogenates. Anal. Biochem. 92, 497-500, 1979

Hartel S., Gossrau R., Hanski C., and Reutter W.: Dipeptidyl peptidase (DPP) IV in rat organs. Comparison of immunohistochemistry and activity histochemistry. Histochem. 89, 151161,1988

Hegen M., Niedobytek G., Klein C.E., Stein H., and Fleischer B.: The T cell triggering molecule Tp103 is associated with dipeptidyl aminopeptidase IV activity. J. Immunol. 144, 2908 2914, 1990.

Hildebrandt M., Reutter W., and Gitlin J.D.: Tissue-specific regulation of dipeptidyl peptidase IV expression during development. Biochem. J. 277, 331-334, 1991.

Hoffmann T., Faust J., Neubert K., and Ansorge S.: Dipeptidyl peptidase IV (CD26) and aminopeptidase N (CD13) catalyzed hydrolysis of cytokines and peptides with N-terminal cytokine sequences. FEBS Let. 336, 61-64, 1993.

Iwata S., and Morimoto Ch.: CD26/dipeptidyl peptidase IV in context: the different roles of a multifunctional ectoenzyme in malignant transformation. J. Exp. Med. 190, 301-305, 1999. 
Johnson R.C., Zhu D., Augustin-Voss H.G., and Pauli B.U.: Lung endothelial dipeptidyl peptidase IV is an adhesion molecule for lung-metastatic rat breast and prostate carcinoma cells. J. Cell. Biol. 121, 1423-1432, 1993.

Kameoka J., Tanaka T., Nojima Y., Schlossman S.F., and Morimoto C.: Direct association of adenosine deaminase with a $\mathrm{T}$ cell activation antigen, CD26. Science 261, 466-469, 1993.

Lojda Z.: Proteinases in pathology. Usefulness of histochemical methods. J. Histochem. Cytochem. 29 (3A Suppl.), 481-493, 1981.

Markwell M.A.K., Haas S.M., Tolbert N.E., and Bieber L.L.: Protein determination in membrane and lipoprotein samples: manual and automated procedures. Met. Enzymol. 72, 296303, 1981.

Medeiros M. dos S., Balmforth A.J., Vaughan P.F., and Turner A.J.: Hydrolysis of atrial and brain natriuretic peptides by the human astrocytoma clone D384 and the neuroblastoma line SH-SYSY. Neuroendocrinol. 54, 295-302, 1991.

Meir E.G.: Cytokines and tumors of the central nervous system. Glia 15, 264-288, 1995.

Mentlein R., Kolszynski M., Sprang R., and Lucius R.: Proline-specific proteases in cultivated neuronal and glial cells. Brain Res. 527, 159-162, 1990
Mentlein R., Dahms P., Grandt D., and Krüger R. Proteolytic processing of neuropeptide Y and peptide YY by dipeptidyl peptidase IV. Regul. Pep. 49, 133-144, 1993.

Palma C., Nardelli F., Manzini S., and Maggi C.A.: Substance $\mathrm{P}$ activates responses correlated with tumour growth in human glioma cell lines bearing tachykinin $\mathrm{NK}_{1}$ receptors. Brit. J. Cancer 79, 2369-243, 1999.

Šedo A., Křepela E., and Kasafírek E.: A kinetic fluorometric assay of dipeptidyl peptidase IV in viable human blood mononuclear cells. Biochimie 71, 757-761, 1989.

Šedo A., and Kraml J.: Dipeptidyl peptidase IV in cell proliferation and differentiation. Sbor. Lék. 95, 295-298, 1994.

Šedo A., and Revoltella R.P.: Detection of dipeptidyl peptidase IV in glioma C6 and neuroblastoma SK-N-SH cell lines. Biochem. Cell. Biol. 73, 113-115, 1994.

Šedo A., Mandys V., and Křepela E.: Cell membrane-bound proteases: not "only" proteolysis. Physiol. Res. 45, 169-176, 1996

Šedo A., Malík R., and Křepela E.: Dipeptidyl peptidase IV in C6 rat glioma cell line differentiation. Biol. Chem. 379, 3944, 1998.

Yaron A., and Naider F.: Proline-dependent structural and biological properties of peptides and proteins. Crit. Rev. Biochem. Mol. Biol. 28, 31-81, 1993. 